\title{
THE 2015 CEOS DISTANCE EDUCATION COURSE ON GEOLOGICAL DISASTERS MANAGEMENT
}

\author{
Mouratidis A. ${ }^{1}$ \\ ${ }^{1}$ Aristotle University of Thessaloniki, Department of Physical \& Environmental Geography, \\ 54124, Thessaloniki, Greece,amourati@geo.auth.gr
}

\begin{abstract}
The purpose of this paper is to present the framework, content, outcomes and the lessons learnt from the 2015 Committee on Earth Observation Satellites (CEOS) course on geological disasters management, delivered within the 2015 CEOS Distance Education Course entitled "Remote Sensing Technology for Disaster Management" - a joint effort by CEOS Agencies, in particular of the Working Group on Capacity Building \& Data Democracy (WGCapD) and the Working Group on Disasters (WGDisasters).

Keywords: Distance Education, e-learning, Capacity Building, Earth Observation from Space, Disasters.
\end{abstract}

\section{Пєрі́ $\eta \psi \eta$}

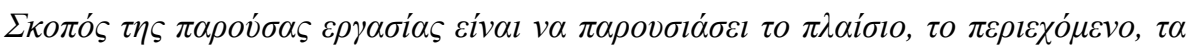

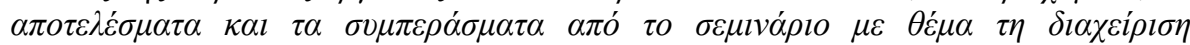

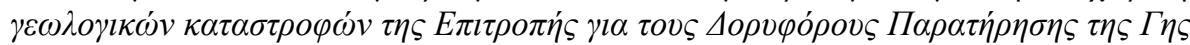

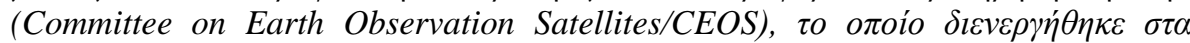
$\pi \lambda \alpha i \sigma l \alpha$

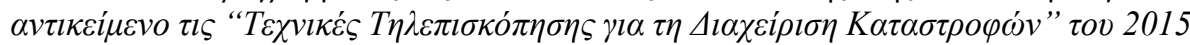

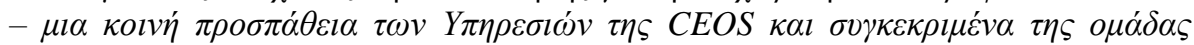

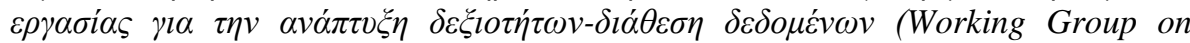

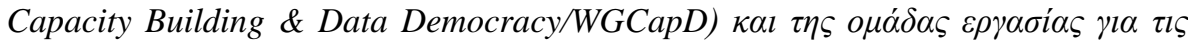

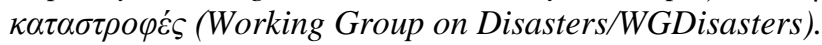

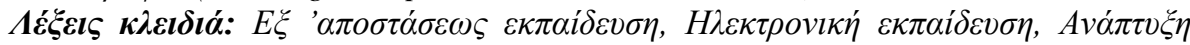

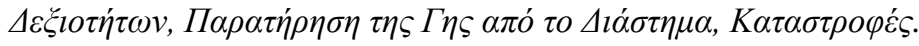

\section{Introduction}

The Committee on Earth Observation Satellites (CEOS, www.ceos.org) was established in 1984 in response to a recommendation from a Panel of Experts on Remote Sensing from Space and set up under the aegis of the G7 Economic Summit of Industrial Nations Working Group on Growth, Technology, and Employment. This Panel recognized the multidisciplinary nature of space-based Earth observations and the value of coordinating international Earth observation efforts to benefit society. CEOS mission is to ensure international coordination of civil space-based Earth observations programs and promote exchange of data to optimize societal benefit and inform decision making for securing a prosperous and sustainable future for humankind.

Today, CEOS includes 31 member Agencies, such as the Ministry of Education, Culture, Sports, Science, and Technology/Japan Aerospace Exploration Agency (MEXT/JAXA), the European Space Agency (ESA), the Russian Federal Service for Hydrometeorology and Environmental 
Monitoring (ROSHYDROMET), the National Aeronautics \& Space Administration (NASA), the Canadian Space Agency (CSA) and the European Commission (EC). Additionally, there are another 28 CEOS associate members, such as the Food and Agriculture Organization of the United Nations (FAO) and other UN Bodies, the World Meteorological Organization (WMO) and the International Society of Photogrammetry and Remote Sensing (ISPRS).

CEOS supports effective societal decision-making in the areas of climate monitoring and research; carbon observations, including observations to support the effective monitoring and management of the world's forested regions; food security; disaster risk management; biodiversity; capacity building; data availability and access; and more.

Education, training, capacity building and outreach are a strong component of CEOS activities, coordinated by the CEOS Working Group on Capacity Building \& Data Democracy (WGCapD) (formed at the $25^{\text {th }}$ CEOS Plenary in 2011, as an evolution of the previous Working Group on Education and Training/WGEdu). WGCapD undertakes a variety of activities, in order to serve its main purposes, i.e. the provision of Data Access, Data Dissemination, Software Tools and Capacity Development. In this context, the WGCapD builds upon the concept of "Data Democracy", in an effort to increase the capacity of institutions in less developed countries for the effective use of Earth observation data for the benefit of society and to achieve sustainable development.

On another front, Disaster Risk Management (DRM) continues to gain political, economic, and geopolitical importance as disasters have caused increasing human and economic losses. These losses are only expected to grow as a result of increasing global urbanization (expected to double by the year 2050) and an increasing number of extreme events (expected to triple by the year 2100).

This situation has resulted in the creation of a dedicated CEOS "Working Group on Disasters" (WGDisasters) in 2013. One of the WGDisasters goals is to develop and strengthen relationships with stakeholder and end- users through a series of concrete actions addressing single-hazard Pilot projects (currently floods, volcanoes, and seismic hazards), multi-hazard projects (such as the Recovery Observatory and the Group on Earth Observations (GEO) Geohazard Supersites and Natural Laboratories (GSNL), and through CEOS capacity building activities for disaster managers. The overarching goals of the WGDisasters are to increase and strengthen satellite Earth observation contributions to the various Disaster Risk Management (DRM) phases and to inform politicians, decision-makers, and major stakeholders on the benefits of using satellite Earth Observations in each of those phases.

In this context, the purpose of this paper is to present the content, outcomes and the lessons learnt from the 2015 CEOS course on geological disasters management, delivered within the 2015 CEOS Distance Education Course entitled "Remote Sensing Technology for Disaster Management" - a joint effort by CEOS Agencies, the WGCapD and WGDisasters in particular, towards:

- Disseminating remote sensing technology among disaster risk management practitioners with an interest in geospatial technology

- $\quad$ Providing wider and easier access to Earth observation data

- Increasing the sharing of software tools such as open source software and open systems interfaces

- Increasing data dissemination capabilities and transferring relevant technologies to disaster risk management practitioners 


\section{Course Description}

\subsection{Overview of the Webinar Series}

This Distance Education Course consisted of a series of introductory webinars addressing the use of remote sensing technology for Disaster Management (DM).

The particular elements making this course unique were that it:

- Was provided free of charge

- Provided access to expertise from space agencies around the world

- $\quad$ Linked participants to a global network of experts and policymakers

- Created awareness about international coordination bodies, such as CEOS, GEO, the United Nations Office for Outer Space Affairs (UNOOSA) and the International Charter for Space and Major Disasters

- $\quad$ Provided access to datasets and useful tools available from CEOS Agencies

- Helped attendees develop skills to aid in Disaster Management (DM).

The following WGCapD members participated, as part of a core team for discussing the course syllabus, structure, and methodology:

- Brazilian Institute of Space Research (INPE)

- Indian Space Research Organisation (ISRO)

- $\quad$ European Space Agency (ESA)

- National Oceanic and Atmospheric Administration (NOAA)

- United States Geological Survey (USGS)

- CEOS Systems Engineering Office (SEO)

Twelve instructor volunteers came from five CEOS Agencies (INPE, ISRO, NASA, ESA and USGS), universities, and training centres, such as the University of Waterloo (Canada), International Space University (ISU), and NASA ARSET (Applied Remote Sensing Training). English was the official course language, while the topics were divided in eight thematic areas - corresponding to eight weekly webinars (webinar four was the one dedicated to geological disasters) - as follows:

1. Introduction to the webinar series

2. Introduction to disasters (Causes, Effects, Monitoring, Mitigation, and Management. Methods of Hazard, Vulnerability, and Risk Assessment and the Role of Geospatial Data.)

3. Space-based Earth Observation Systems and their Applications for Hydro- meteorological Disasters (Floods)

4. Space-based Earth Observation Systems and their Applications for Geological Disasters (Earthquakes, Landslides, and Volcanoes)

5. Space-based Earth Observation Systems for Environmental Disasters (Forest Fires)

6. Real Time Monitoring of Global Precipitation from Space: New Technologies Applied to Heavy Rainfall Risk Reduction

7. Concepts and Applications of Internet GIS and Sensor Web (Network of Sensors) for Disaster Management. Example of an open source tool (TerraMA2. a Computational Platform for Developing Monitoring, Analysis, and Alert Systems) 


\section{Rapid Mapping and Emergency Services: Success Stories}

In March 2015, the course was advertised via the CEOS website, CEOS internal mailing lists, the Virtual Laboratory for Education and Training in Satellite Meteorology (VLab) Newsletter, the INPE mailing list, the ISU mailing list, the AfriGEOSS Initiative mailing list, and a special list of previous students from another course. Social media channels (Facebook and Twitter) were also used for this purpose.

The course webpage (http://ceos.org/meetings/wgcapd-distance-education-2015), part of the CEOS website, provided a link to the online application form.

The course was based on the online distance education program principles that allow participants to fully engage with program content, their peers and their instructors via live lectures, questions/answers through discussion forums, as well as feedback mechanisms. For self-assessment purposes, brief quizzes were available after each webinar.

Course materials included well-organized presentations, selected datasets, and various resources from the internet. A GoToWebinar license (funded by INPE) was used, in order to hold one live classroom session per week, which was recorded and made available for download afterwards. Students were provided with free and open access to a variety of resources, software tools, and datasets.

Moodle (Modular Object-Oriented Dynamic Learning Environment), hosted at INPE, was utilized for course administration, documentation, tracking, reporting, and delivery. Moodle helped foster interaction between instructors and students with different backgrounds.

The pre-webinar and post-webinar phases of this course required significant effort. In the prewebinar phase, instructors uploaded their learning materials to Moodle, prepared their course quiz questions, and developed their 1-hour lectures for presentation during the webinar (including 10 minutes for questions). The GoToWebinar System allowed the interaction with students, with features such as registration, invitations, and reminders. Practice-sessions with course instructors were also held one week before webinars, in order to familiarize them with the software, material, and organizational flow. The post-webinar phase included the compilation of surveys and questions to be posted on the discussion forum. Instructors were advised to log in to Moodle during the week of their webinar at least once a day, in order to answer student questions inside the Course Discussion Forum.

In the beginning, access to course materials required user authentication in Moodle, but later on course materials were made freely and publicly available on the Course Wiki, as motivated by the Open Educational Resources initiative.

\subsection{Course on Geological Disasters Management}

As per the organizational requirements, the course on geological disasters included a 1-hour webinar, with subsequent discussions via Moodle during a full week between 28 April - 4 May 2015.

A tragic happenstance was that the webinar coincided with the devastating Kathmandu, Nepal, earthquake on April 25 ( $\mathrm{M} \approx 8$, with thousands of casualties) - just a couple of days before the online course - making the thematic of the specific webinar very timely and probably more "attractive" for the participants.

The webinar consisted of short introduction of the instructor (with video on), followed by a presentation of about 80 slides (with video off, in order to save bandwidth). The presentation was divided in four major parts, namely:

- Overview of geological disasters

- $\quad$ Relevant Space-based EO systems, data and techniques 
- Synergy with other EO systems and geospatial technology

- Applications - case studies (Earthquakes, Landslides, Volcanoes)

The last 10 minutes of the webinar were dedicated to answering questions.

The short self-assessment quiz consisted of five questions, focusing on important aspects and conclusions of the webinar (Figure 1).

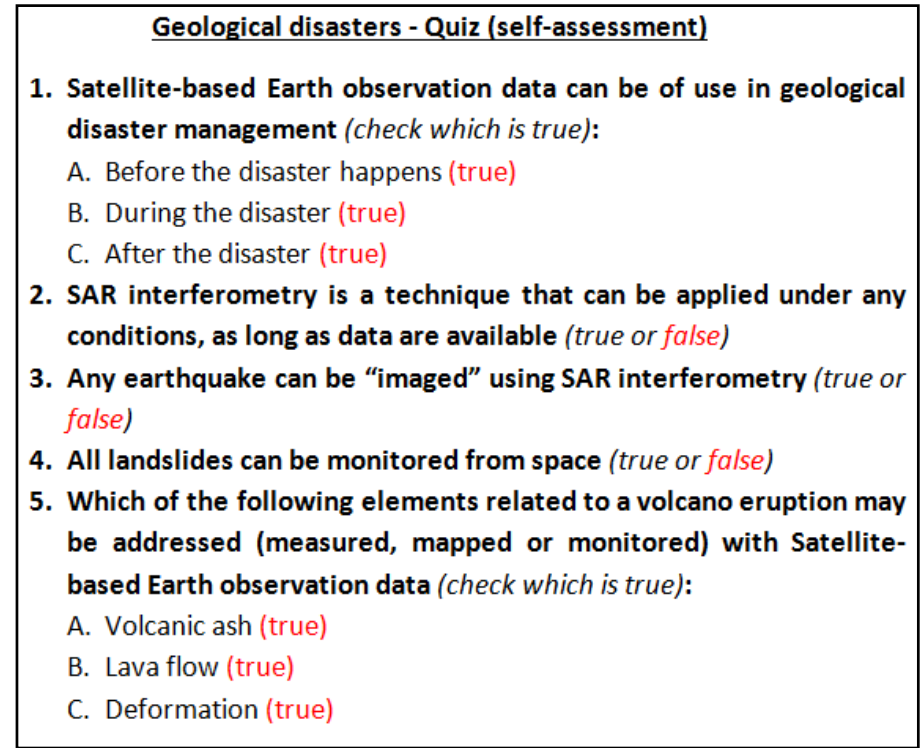

Figure 18 - Questions and answers of the post-webinar self-assessment quiz.

The following week was dedicated to questions and answers, but also lively discussions via Moodle, partly triggered from the Nepal earthquake and fresh results coming in from Earth observation data of various space agencies around the world during the next few days.

\section{Participant Profile}

This course was open to participants from anywhere in the world. Its target audience included Disaster Management practitioners with an interest in geospatial technology, with a perquisite for elementary knowledge about remote sensing, Geographic Information Systems (GIS), and digital image processing.

144 students initially registered for the course, but, due to GoToWebinar constraints, only 99 of them could be accepted on a first-come first-served basis. The geographic distribution of course applicants by continent is shown in Figure 2 . 


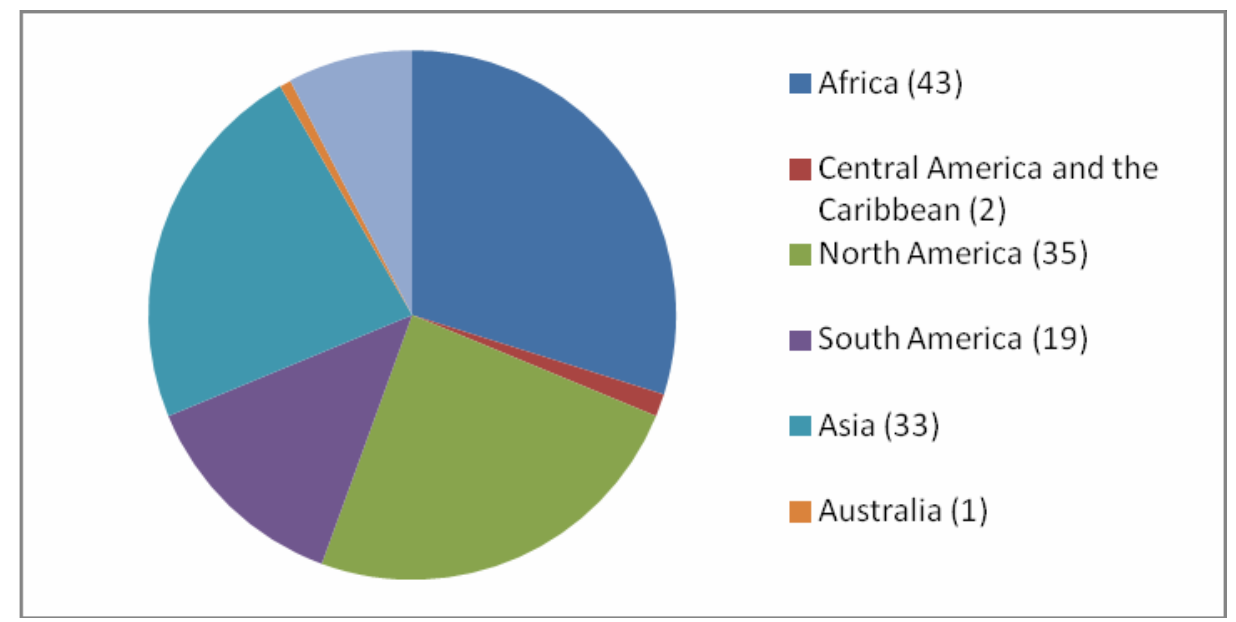

Figure 2 - Geographic distribution of registrations for the webinar series (source: CEOS WGCapD, 2015).

All students selected had a bachelor's degrees or higher, in a wide variety of disciplines: Geography, Science, Engineering, Agronomy, Geology, Physics, Hydrology, Computer Science, Meteorology, and more. Forty-two students held a Master of Science degree, and 11 held doctoral degrees. Most of them either had remote-sensing and GIS specializations or had been working in the field for many years.

Student affiliations included universities, United Nations Regional Centres, Regional Centres, Government, Private Sector and Non-Governmental Organizations (NGOs).

Most students were interested in taking the course for professional, academic and personal development, expecting to deepen their knowledge on the use of satellite imagery and tools for disaster management, improve their understanding of remote-sensing technology, and stay up-todate with the latest trends and applications in this important field.

\section{Results}

Webinar session attendance decreased as the course progressed. By the end of the course, only 46 out of the 99 enrolled students received a Certificate of Participation. Six students who participated in the CEOS International E-learning Course on Introduction to Remote Sensing Technology (2013) also enrolled for this course and successfully completed it.

Initially, the criterion for receiving the Certificate was attendance for all live webinar sessions. However, it was later decided that on-going participation in quizzes and the discussion forums also demonstrated active participation, so it was decided to provide the Certificate to students who attended at least four live sessions and attempted at least four quizzes. Throughout the course, many students sent emails apologizing for not attending specific sessions due to their job duties.

Some students did not attend the live sessions, but did access the recordings and take the quizzes afterwards (Figure 3).

The quizzes were optional and were meant for self-assessment purposes only. Table 1 shows the number of students that took the quizzes (only nine students took all the quizzes, and the average score was 78.9/100).

Students were asked to participate in a follow-up survey on Moodle to evaluate the effectiveness of the course and receive feedback on how to improve the course. 46 students ( 37 of which successfully 
completed the course and nine that did not) completed the survey, which included yes/no, multiple choice, and open-ended questions (Figures 4-6).

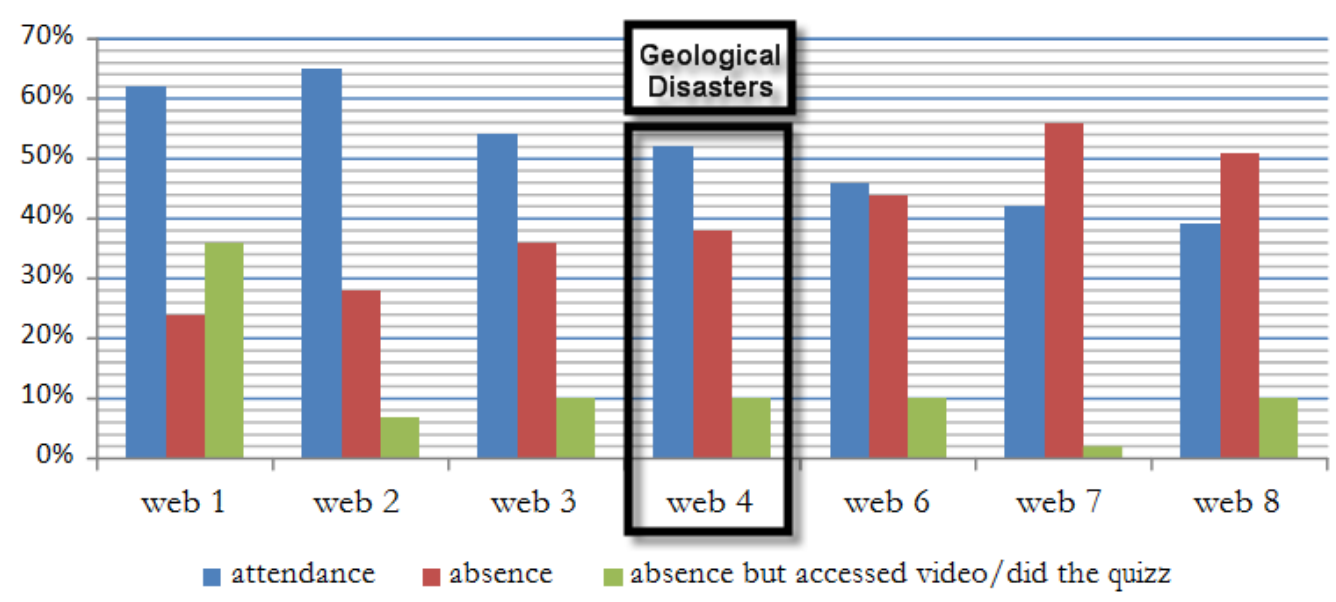

Figure 3 - Attendance of the Geological Disasters webinar. Webinar 5 has been omitted due to unforeseen events for which the live presentation had to be cancelled (source: CEOS WGCapD, 2015).

Table 1 - Number of students who completed the quiz for each webinar.

\begin{tabular}{|l|c|c|c|c|c|c|c|}
\hline Quiz 1 & Quiz 2 & Quiz 3 & Quiz 4 & Quiz 5 & Quiz 6 & Quiz 7 & Quiz 8 \\
\hline 30 & 30 & 37 & $\mathbf{4 1}$ & - & 24 & 23 & 18 \\
\hline
\end{tabular}

The overall rating of the course series was very positive, as it can be deducted from Figure 4. In addition to that $100 \%$ of the students said that they would recommend this or a similar webinar series to a colleague/friend to attend in the future.

The students also evaluated the software used during the course (Moodle and GoToWebinar), the learning materials (presentations, quizzes, and tutorials), the instructors' performances, and the course contents. In general, all of these items scored very well, most of them scoring Good, Very Good, and Excellent (Figure 5).

The thematic area of geological disasters was in the middle of the overall course, thus attendance was average, given its progressive decreasing tendency over the eight weeks (Figure 3). Nevertheless, the webinar on geological disasters received the highest score among all webinars, in terms of usefulness for the participants (Figure 6) and it also had the highest participation concerning the associated quiz (Table 1).

For $26 \%$ of the students, this was their first online education experience, and $63 \%$ said they preferred on-line courses over classroom courses. The main advantage mentioned for taking on-line courses was the ability to attend the lectures without having to travel to the class, saving money and time that would otherwise be spent on transportation. A small number of students reported internet connection issues, but since the on-line sessions were recorded, they were able to download and watch them later.

The successful participants received a congratulations email together with the attached Certificate of Participation. Certificates were issued by the CEOS SEO. The instructors also received a Certificate of Appreciation. 


\section{Your overall rating of this course:}

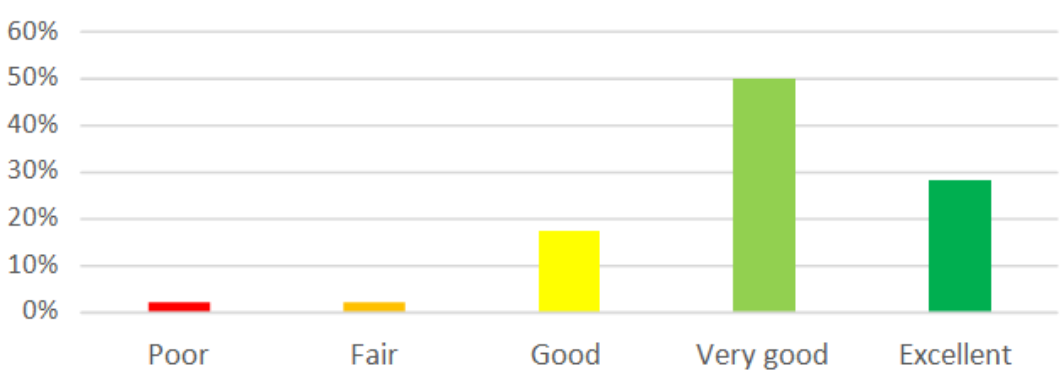

Figure 4 - Overall course evaluation from the students (source: CEOS WGCapD, 2015).

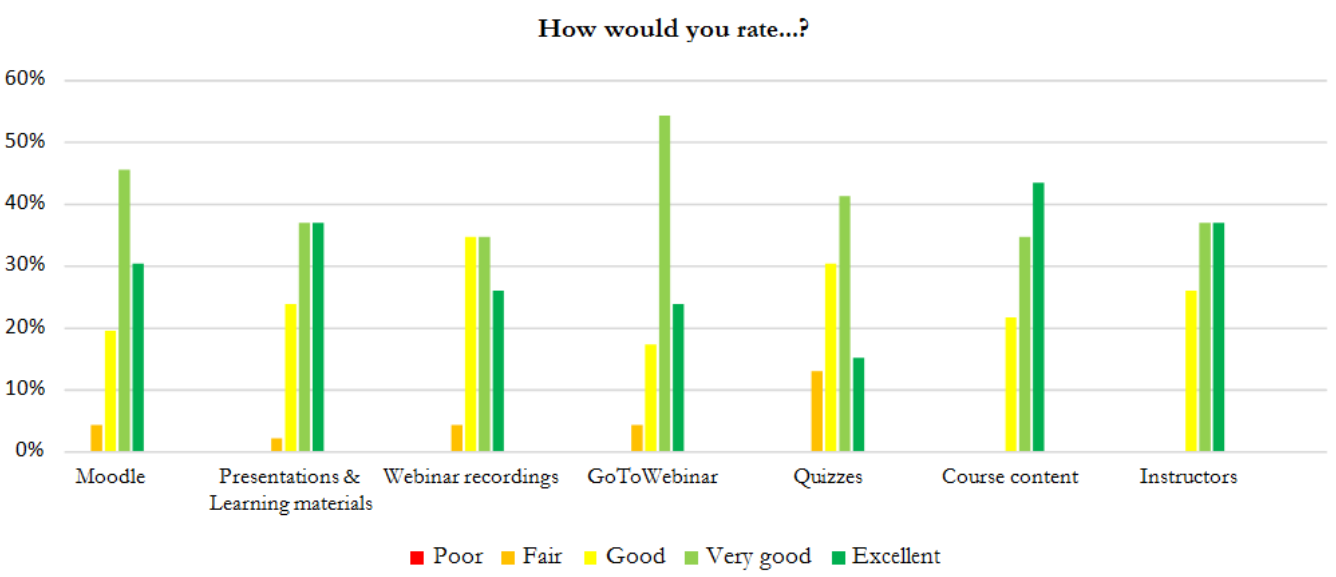

Figure 5 - Detailed course evaluation from the participants (source: CEOS WGCapD, 2015).

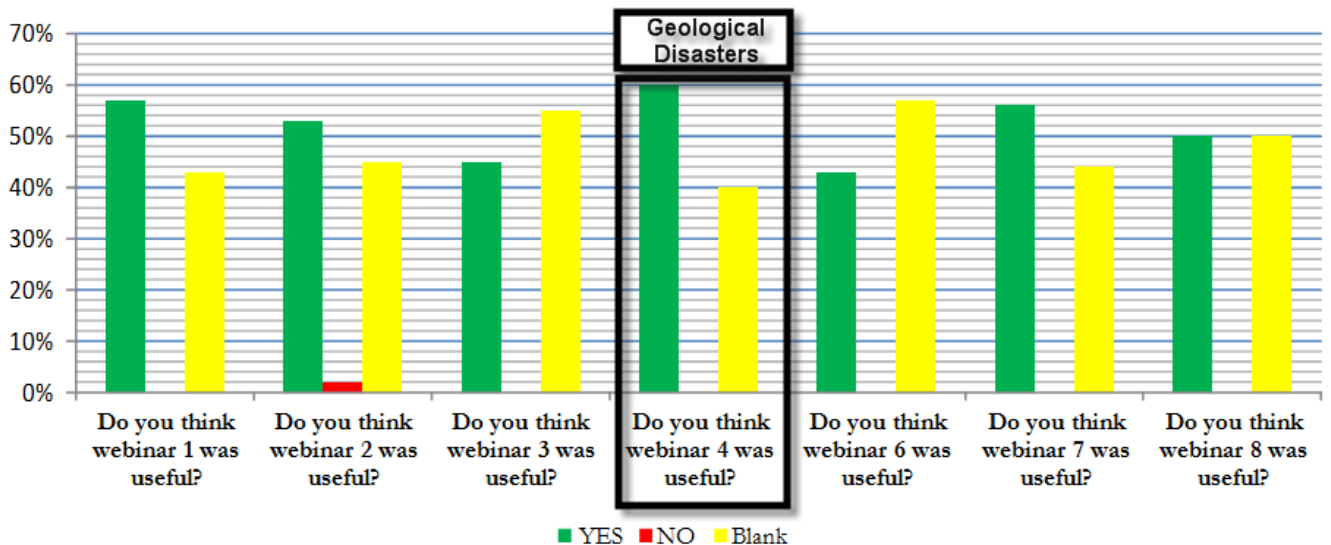

Figure 6 - Student feedback regarding the usefulness of each of the webinars (source: CEOS WGCapD, 2015).

\section{Conclusions}

Including participants from all continents, this course successfully provided students with a multicultural educational experience in Remote Sensing as applied to Disaster Management. 
As per the overall course conclusions (CEOS WGCapD, 2015), this learning activity created awareness about international coordination bodies, such as CEOS, Group on Earth Observations (GEO) and the International Charter for Space and Major Disasters, as major sources of data for DM. It also enhanced the knowledge about data availability through the International Charter during a disaster and how it can be activated. Furthermore, it increased knowledge on the use of satellite Earth observation data from different sources for DM and on how to determine which specific GIS capabilities and data types are required to support emergency management work before, during, and after a disaster strikes. Overall, it improved student ability to advise decision makers about how to use space technology for DM.

Although it was emphasized (in the announcement, course syllabus, etc.) that this was a distance course that would integrate webinar technology with a longer-term online learning environment (Moodle), student interaction via the discussion forums (the main tool for asynchronous communication) was very low. This may have resulted from a misconception about the course methodology. Webinars (virtual seminars), by definition, differ from online courses in that online courses span a greater time frame and engage students in continuous online discussion threads about topics and assignments. However, due to low levels of interaction, the goal to generate new contacts and interaction between students and other professionals worldwide was not achieved.

The biggest challenges faced by instructors during the webinar sessions were centered on how to keep the students engaged in the online learning setting (e.g. appropriate presentation length and format). Instructors used polls and surveys during the webinars in an effort to prevent students from losing focus and engaging too heavily in unrelated tasks during the webinars (i.e. multitasking). Polls and surveys also help instructors gauge how well the students are understanding the information (or how much they already know).

The presence of a moderator in each of the webinars helped troubleshoot webinar technology without distracting the instructors. The moderator also assisted in managing questions from students during the session. For similar future courses, limiting the webinar lectures to 45 minutes and allowing more time for questions and interaction with students should be considered. Additionally, the feedback and suggestions from students reflect their need for more hands-on activities and software/real scenarios demonstrations. This will also be considered when planning future courses.

Finally, concerning the course on geological disasters in particular, it received increased interest from the participants. Therefore, it seems that the Nepal earthquake, which was practically synchronous with the relevant thematic area discussed during that week, must have had some influence in this respect. Nevertheless, it should not be neglected that the nature and effects of a disaster such as an earthquake, or the impressive images of erupting volcanoes and - to a lesser extent - major landslide events, especially when seen from Space, are possibly attracting somewhat more attention than other topics.

\section{Acknowledgments}

CEOS WGCapD and WGDisasters members are gratefully acknowledged for making the realization of this course possible and providing a unique opportunity to learners, but also teachers from around the world. Co-instructors are to be thanked for the fruitful collaboration and exchange of comments and ideas during the preparatory actions, as well as during and after the webinar series. Special thanks are extended to Hilcéa Ferreira (INPE) and S.P. Aggarwal (IIRS/ISRO) for their outstanding efforts in coordinating the whole initiative.

\section{References}

CEOS WGCapD, 2015. Evaluation Report for the WGCapD \& WGDisasters Distance Education Course: A Webinar Series on Remote Sensing Technology for Disaster Management, April $6^{\text {th }}-$ May $31^{\text {st }}, 2015$. 